\title{
The Impact of Fertilizer Subsidy on Paddy Cultivation in Sri Lanka
}

\author{
H. K. J. Ekanayake ${ }^{1}$
}

\begin{abstract}
The Government of Sri Lanka has been subsidizing fertilizer for more than four decades. This study attempts to analyse the impact of fertilizer subsidies with reference to paddy cultivation in Sri Lanka. The issue is analysed by employing three separate demand functions for major fertilizers by using simple regression model. Regression results indicate that changes in the prices of fertilizer and paddy do not have a significant effect on fertilizer usage, which points to the fact that the fertilizer subsidy is not a key determinant of the use of fertilizer in paddy cultivation. The study also found that there is a relatively higher correlation between fertilizer usage and paddy price than between fertilizer usage and fertilizer price. These findings suggest that the fertilizer subsidy could be withdrawn gradually over time. In its place, appropriate infrastructure and institutional facilities that are required to increase productivity in paddy cultivation and an effective mechanism for marketing the output that would result in favourable prices for paddy may be introduced for a more effective outcome. (JEL N551, Q19)
\end{abstract}

\section{Introduction}

Paddy production in Sri Lanka has increased considerably during the last three decades as a result of cultivation of high yielding varieties, increase in the area of cultivation under irrigation and greater use of plant nutrients. Successive governments have also provided support to stimulate paddy production by way of introducing guaranteed price schemes, major irrigation schemes and fertilizer subsidy schemes. Introduction of high yielding varieties was the major factor, which contributed to increase in paddy production in the country. Given that high yielding varieties are highly fertilizer responsive, proper fertilizer

1/ The views expressed in this paper are the author's own and do not necessarily reflect those of the Central Bank of Sri Lanka. 
application is needed to obtain respective yield levels. With respect to paddy, the supply of three major nutrients namely, Nitrogen (N) Phosporous (P) and Potassium (K) are essential for cultivation. Among these nutrients Nitrogen is a major nutrient demanded by paddy plants to increase yield. Since, over use and misuse of these fertilizer can reduce yields and also make soil less productive, fertilizer recommendations are done by respective crop research institutions of the country. Fertilizer recommendation for paddy is given in Appendix I.

Figure 1 : Annual Paddy Production and Fertilizer usage in Paddy Cultivation

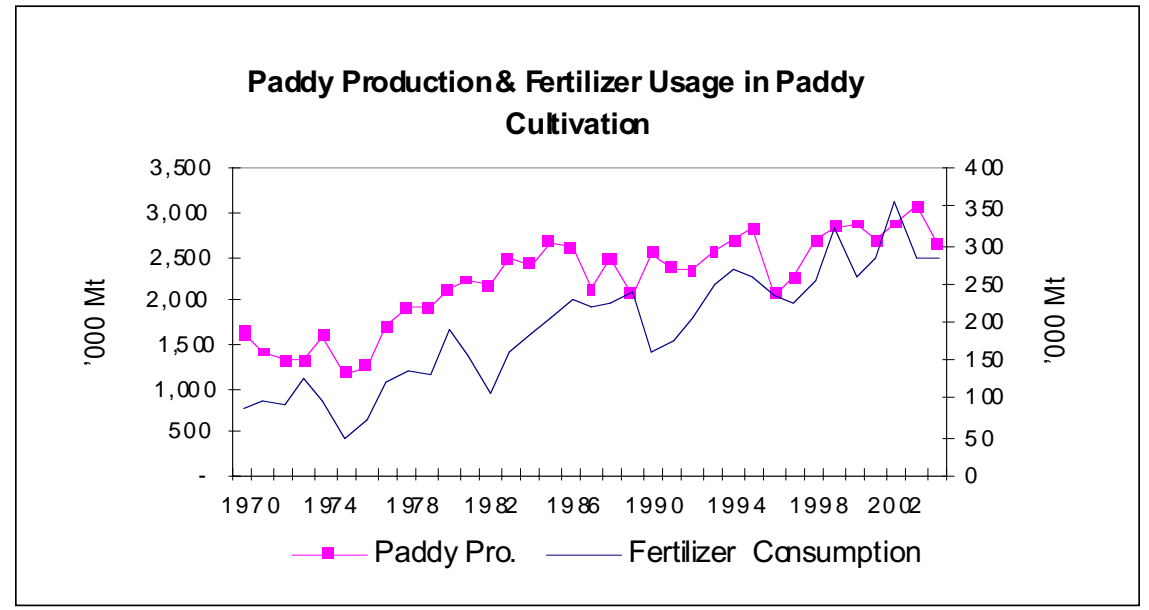

Because of the importance of fertilizers in increasing agricultural output, government intervention in the fertilizer market started in 1962 with the introduction of fertilizer subsidy scheme. The main objective of the subsidy scheme was to make fertilizer available as cheaply as possible in order to encourage its wider use thereby increasing agriculture productivity. The fertilizer subsidy has been available for more than four decades even though with several changes, farmers expect it to be continued in the future. Meanwhile, the government faces great difficulty with the increasing expenditure on the fertilizer subsidy mainly in recent times due to its fiscal implications. Expenditure on fertilizer subsidy in Sri Lanka has gone up from Rs.600 million in 1987 to Rs. 3,572 million in 2004. This was further increased to Rs. $6,846 \mathrm{mn}$ in 2005. Public expenditure on fertilizer subsidy scheme for last 10 years is given in Appendix II. Therefore, the purpose of this study is (i) to analyse the fertilizer subsidy scheme on paddy cultivation on the basis of the estimated fertilizer demand functions and (ii) to elaborate other measures that can be used as alternatives to the fertilizer subsidy policy. 
In order to analyse these issues this paper is organized as follows. The rest of this section explains the history and evolution of fertilizer subsidy policy in Sri Lanka. Section II reviews the existing literature on the subject. Section III discusses the data and econometric tools used in this study while in section IV presents the results of the econometric regressions. Section V concludes the discussion on impact of fertilizer subsidy policy on paddy cultivation.

\section{A. Evolution of Fertilizer subsidy policy in Sri Lanka}

As fertilizer is an essential input in agriculture strong fertilizer related policies are crucial for any national effort aiming at improving agricultural productivity. As a major step towards achieving this objective, the government of Sri Lanka introduced a price subsidy for fertilizer in 1962. The main objective of the subsidy scheme was to make fertilizer available as cheaply as possible in order to encourage its wider use. A lower fertilizer price reduces cost of production and increases demand for fertilizer and for other inputs depending on the elasticity of substitution, income effect and elasticity of supply of other inputs. If sufficient quantities of fertilizers are available to meet the increased demand and if the additional fertilizer is properly applied, food production will increase.

Initially four main fertilizers namely, Urea, Sulphate of Amonia, Muriete of Potash (MOP) and Triple Super Phosphate (TSP), which provide Nitrogen $(\mathrm{N})$, Phosperous $(\mathrm{P})$ and Potassium (K), respectively were subsidized at different rates. Until 1975, the subsidy level varied according to the type of crop. This scheme was found to be unsuccessful as it allowed unauthorized leakages of fertilizer between agricultural sub sectors. Hence, in 1975 the government introduced a uniform subsidy scheme for all crop sectors. Subsidy rates were varied according to the type of fertilizer and the subsidy rates were subjected to revision overtime. Later, in 1990 the government completely removed the fertilizer subsidy for all types of fertilizer, as it was heavy burden on the government budget. However, due to various other reasons fertilizer subsidy scheme was reintroduced in 1994. During the period 1994 to 1997 , the fertilizer subsidy scheme underwent several changes and in 1997 the government decided to restrict the fertilizer subsidy only to Urea. The objective of the new scheme was to provide a higher benefit to paddy farmers while reducing the burden on the government budget. This scheme was also subjected to revision on a seasonal basis. During this period subsidy had been given in either of the following two ways.

1. Selling price of fertilizer is fixed allowing the subsidy component to vary depending on the import price

2. Subsidy component is fixed allowing the selling price of fertilizer to vary. 
During the late 90's the selling price was fixed with the intension of reducing the burden on the farming community due to price fluctuations. Since the price was fixed with a variable subsidy component there was no incentive to the importers to import fertilizer when the world market prices were low. To address this issue the government decided to fix the subsidy component and allow the selling price to vary depending on the world market prices. When the international prices were very high it had an adverse impact on the farmers as the cost of production increased with the increase in fertilizer prices. This situation created financial difficulties particularly for small farmers in the dry zone where paddy cultivation largely exist. Therefore, again in 2004 the government decided to fix retail price of fertilizer. This system continued until December 2005. In December 2005, the government decided to reintroduce subsidy scheme for all types of fertilizer by fixing their selling price. However, this scheme is restricted only for paddy farmers.

\section{Literature Review}

There are many studies that have estimated the demand for fertilizer or for the specific nutrients (Nitrogen, Phosphorous and Potassium). In developed countries, it is generally agreed that fertilizer demand is price inelastic. This may be due to lack of an economic substitute to chemical fertilizer. Generally, in less developed countries the demand for fertilizer is thought to be more elastic under the assumption of readily available substitutes such as manure and other organic materials. However, the demand for fertilizer may differ from country to country due to the factors such as cultural practices, climate, soil type, crops grown and farm structure. In this section, an attempt is made to review several of impotent research work on the subject.

The demand for fertilizer as a main input in agriculture has been the focus of many studies over the years. The early studies include work by Griliches (1958, 1959), Heady and Yeh, Carman, Gunjal, Roberts and Heady, and others. In general, emphasis has been on national or regional demand estimates for total fertilizer or nutrient application on all crops. Griliches (1958) estimated the aggregate demand functions for fertilizer use on all crops in the United States. He showed that for the 1911 to 1956 period, most of the increase in fertilizer use could be explained by changes in both fertilizer and crop prices, and by the previous period's use. Using the same model, Griliches (1959) estimated regional demand functions for total fertilizer consumption over the 1931 to 1956 period. While the model explained a large portion of the variation in the regional fertilizer use, he found that estimated price elasticities of demand varied across regions, ranging from elastic to inelastic. 
Heady and Yeh (1959) estimated fertilizer demand functions for total fertilizer and for individual nutrient used on all crops in the United States. The variables affecting the use included fertilizer prices, crop prices, total cash receipts from crops, total crop acreage, acres of specific crops, wage rates, the wholesale price index, and time. In addition, they estimated relationships for total fertilizer use in ten different geographical regions of the United States. Their study allowed a comparison between aggregate fertilizer and individual demand elasticities. Heady and Yeh estimated a shortrun elasticity ranging from about -0.49 to -1.71 for total fertilizers, and elasticities of $-0.45,-0.45$ and -0.40 for nitrogen, phosphate and potash. Those results confirmed that the demand for N, P and K in the U.S. is inelastic.

There have been many studies conducted on fertilizer demand in countries other than the United States. Boyle (1982) used a cost function approach (translog) to estimate fertilizer demand and to obtain estimates of the demand elasticities of nitrogen, phosphorous and potassium in the Republic of Ireland. The major objective of his paper was to test the hypothesis of nutrient substitution over time. His findings suggested inelastic own-elasticities for phosphorous and potassium, and an elastic own-elasticity for nitrogen, and significant cross-price elasticities between nitrogen, phosphorous, potassium. He found that the adverse effects of own-price increases on the consumption of nitrogen would be offset by substitution of nitrogen for phosphorous and potassium.

Burrell (1982) had estimated the demand for fertilizer in the United Kingdom. He used three different modeling approaches with two different data sets (nitrogen, and all fertilizers). He found that the elasticity with respect to crop price is about -0.4 to -0.5 for nitrogen and between -0.1 and -0.3 for all fertilizer in most versions of the system model. This means that demand for nitrogen fertilizer is more sensitive to its own price than is the case for phosphate and potash fertilizer.

Gunawardena P. and Flinn C.J. (1987) in their analysis of supply response and fertilizer demand in rice sector in Sri Lanka, estimated short run production elasticities by using micro level data. They concluded that, both own price elasticity (0.15) and cross price elasticities with respect to hired labour $(-0.12)$ and fertilizer $(-0.01)$ indicated an inelastic production response implying a relatively small incentive to increase paddy production in response to increase in the price of paddy, or reduction in the price of fertilizer. Hence, the results suggested that the guaranteed price scheme and the fertilizer subsidy provide small incentive to increase paddy production.

Chandrapala H.A. and De Silva S. examined the economics of fertilizer use in Major crop sectors of Sri Lanka in 1988. They analysed some economic aspects of fertilizer use in the tea, rubber, coconut and paddy sectors of Sri 
Lanka. Regression models estimated for fertilizer use indicated that the relative price ratio of fertilizer and the output has a significant effect on fertilizer use, which points out the fact that the removal of the subsidy for fertilizer will further worsen the situation with respect to fertilizer use in these sectors.

\section{Data and Model used}

\section{A. Description of Data}

As mentioned earlier, the objective of this paper is to analyse factors affecting fertilizer demand and to investigate the impact of fertilizer subsidy in paddy cultivation. Generally, three main fertilizers are being used in paddy cultivation namely, Urea, Muriate of Potash (MOP), and Triple Super Phosphate (TSP). Therefore, factors affecting the usage (demand) of these fertilizers analysed separately. The Study consists of two main parts.

\section{General analysis of Fertilizer Subsidy Scheme}

The Fertilizer Subsidy scheme divided into three periods according to nature of the subsidy.

1. Period I - Subsidy provided for three main fertilizers (1962-1989, 1995-1996)

2. Period II - Period of Subsidy removal (1990-1994)

3. Period III - Subsidy provided only for Urea (1997-2005)

Since, data is not sufficient to run statistical programme for each of these periods, all the variables that relate to fertilizer usage are presented graphically and analysed to illustrate the changes in those variables in different periods.

\section{Estimation of Fertilizer Demand Function}

Factors affecting the demand of three main fertilizers namely, Urea, Muriate of Potash (MOP), and Triple Super Phosphate (TSP) analysed separately.

Factors affecting the fertilizer application can be listed as follows:

1. Fertilizer Prices (Rs./mt) 
2. Paddy Prices (Rs./mt)

3. Extent under irrigation schemes (Ha)

4. Policy changes

Separate fertilizer demand functions were specified for the three main fertilizers, since the fertilizer subsidy scheme has been changed according to the fertilizer type. Regression models were specified for annual issues of fertilizer at the national level as dependent variables and current fertilizer price and lagged nominal farm gate price and extent under irrigation schemes as independent variables assuming all other factors that influence fertilizer use were remained unchanged. Dummy variables are used to interpret policy changes. Further, it was also assumed that total amount of different fertilizers issued for paddy cultivation during the given year were utilized fully for paddy during the year and no carry over stocks. This assumption was made due to lack of information regarding quantities of paddy fertilizers that were used for the cultivation of other food crops. Own price and cross price elasticities of demand can be obtained from estimated demand function and those elasticities explain the sensitivity (elasiticity) of fertilizer demand to change in fertilizer prices and paddy prices which implies the impact of fertilizer subsidy policy on paddy cultivation.

\section{B. Description of Econometric tools used}

Several econometric tests were carried out to estimate the fertilizer demand function and to analyse the impact of fertilizer subsidy scheme in paddy cultivation. These methods are explained bellow.

\section{Unit root test}

Before estimating the models, it is essential to verify whether the series analysed are stationary or not, and whether there are one or several long run equilibrium relationships between them. If a series is stationary it means, its variance and autocovariences are independent of time. In order to test for unit root to see whether these variables are level stationary (I) or first difference stationary (I (I)), the Augmented Dickey- Fuller (ADF) test is carried out. If a series is found to be (I (I)) then first difference may have to be used in analyzing the relationship. 


\section{Regression Test}

The natural logarithm values of all the variables were used to estimate fertilizer demand function by using simple linear regression model. The model is as follows:

$$
\begin{aligned}
\mathbf{Q}_{t} & =\mathbf{f}\left\{\left(\mathbf{P}_{(f)(t)}\right),\left(\mathbf{P}_{(p)(t-1)}\right),\left(\mathbf{E}_{(p)(t)}\right),(\mathbf{D})\right\} \\
\mathrm{Q}_{t} & - \text { Quantity of fertilizer }(\mathrm{mt}) \text { used in year } t \\
\mathrm{P}_{(f)(t)} & - \text { Price of Fertilizer (Rs./mt) in year } t \\
\mathrm{P}_{(p)(t-1)} & - \text { Farm Gate price paddy (Rs./mt) in year } t-1 \\
\mathrm{E}_{(p)(t)} & - \text { Paddy Extent under Irrigation in year } t \\
\mathrm{D} & - \text { Dummy for policy changes }
\end{aligned}
$$

\section{Results and Discussion}

In this section, the data described in section III are illustrated graphically and those data are used to carry out the analysis of the fertilizer demand functions for paddy cultivation in Sri Lanka by using the statistical and econometric methods explained earlier. Fertilizer demand functions were estimated separately for the different fertilizers, and the results discussed separately under each fertilizer.

\section{A. General analysis of Fertilizer Subsidy Scheme}

\section{Period I - subsidy provided for three main Fertilizers}

During the period from 1962 to 1989 the subsidy scheme was continued for all main fertilizers, which provide N, P, K to plants. Since, data are not available from the beginning, data from 1980 to 1989 are used to represent the period.

During the period under review, usage of all three fertilizers increased continuously. However, the ratio between three fertilizers was almost maintained. A remarkable up rise in Urea consumption in 1980 was mainly due to the low level of retail price (Rs.980/mt) prevailed during the year. Fertilizer prices reduced sharply since the government increased its subsidy rate from uniform subsidy of 50 per cent of Cost and Freight (C\&F) price of fertilizers to 85 per cent, 75 per cent, 75 per cent of the C\&F price of Urea, 
Figure 2 : Changes in Fertilizer Usage in Period I

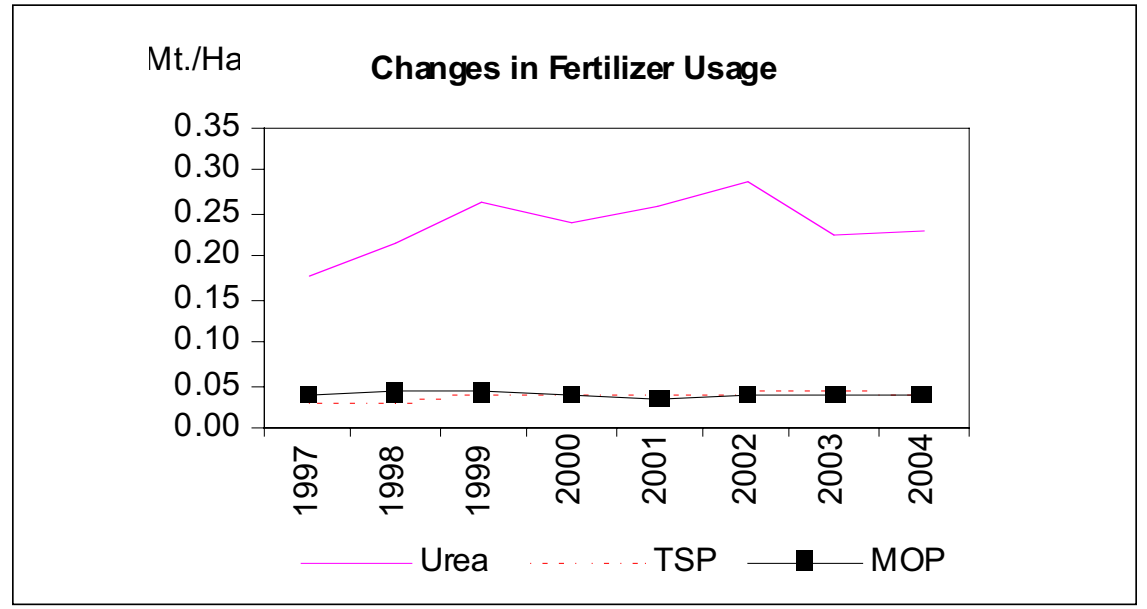

MOP, TSP respectively. However, in 1981 the world market fertilizer prices increased and its impact was severe with the deterioration of Rs./US\$ exchange rate. Hence, the government allowed fertilizer prices to increase by about 30 per cent by rearranging the subsidy components to 65 per cent, 65 per cent and 40 per cent of C\&F prices of Urea, MOP and TSP ,respectively.

This resulted in shortfall in fertilizer consumption in paddy cultivation in 1981. Since then until 1984, fertilizer consumption remained almost stable even though with several changes in subsidy components and retail prices. In 1984 while the prices of fertilizer remained stable, farmers enjoyed an increase in the guaranteed price of paddy. As a result fertilizer consumption triggered upward. This trend continued until termination of fertilizer subsidy scheme by the government in 1989 .

Figure 3 : Changes in Fertilizer Price and Farm gate Price of Paddy in Period I

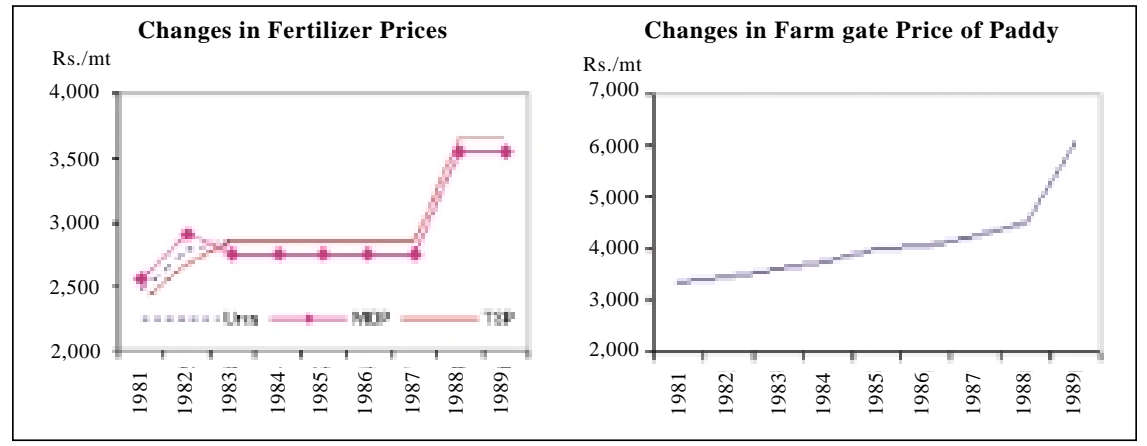


The selling prices of fertilizer during this period is determined by the National Fertilizer Secretariat in consultation with fertilizer whole sellers taking in to consideration the cost of fertilizer and the subsidies made available by the government. Therefore, subsequent to the reduction in the fertilizer subsidies, an increase in the prices of subsidized fertilizers could occur. Accordingly an increase in retail price of fertilizer observed in 1983 due to the reduction of subsidy by around 15 per cent of C\&F cost of fertilizer. These fertilizer prices were not revised until 1988. In 1988 there was a sharp escalation in the cost of fertilizer in the international market. Hence it became necessary to increase the local price of fertilizers by reducing subsidy component. Accordingly prices of three major fertilizers increased by around 30 percent in 1988 . Increasing trend in paddy prices continued during the period. However, in $1988 / 89$ period, there was a sharp increase in the farm gate price of paddy as the government increased guaranteed price of paddy mainly to cushion farmers from the adverse impact of higher fertilizer prices.

\section{Period II (1990-1994) - Period of Subsidy Removal}

Increasing fertilizer prices in the international market with rising oil prices together with depreciation of exchange rate caused considerable difficulties in maintaining the fertilizer prices unchanged during 1989. Hence, the fertilizer subsidy was completely withdrawn by the government with effect from 1 January 1990. With the removal of fertilizer subsidy there was sharp escalation of fertilizer prices from the beginning of 1990. The total use of

Figure 4 : Changes in Fertilizer Usage in Period II

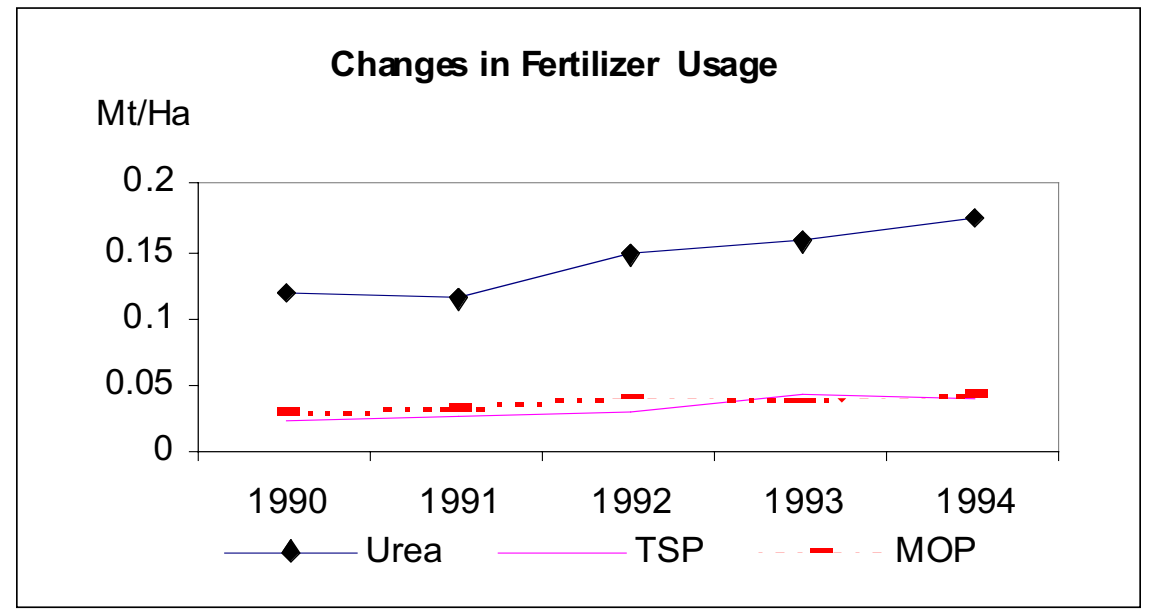


fertilizer declined in 1990, in the wake of increase in fertilizer prices due to the removal of the subsidy. However, the decrease in consumption was not as high as was anticipated. It may well be that in anticipation of a price increase in 1990 after removal of the subsidy farmers stocked their requirement for their crops. Further, with the removal of the subsidy, in order to cushion the adverse impact of sudden price increases of fertilizer, government revised upward the guaranteed price of paddy.

In the years of 1991,1992, and in 1993, the overall consumption of fertilizer increased by 3.5 per cent, 16.0 per cent and 17.0 per cent respectively indicating that most of the farmers were gradually adjusting themselves to the new prices. Furthermore, other scheme such as granting of credit in kind for purchasing of seed and fertilizer under the agricultural trust fund and the favourable farm gate price for paddy were some of the important factors contributed to this improvement.

The sharp increase in fertilizer consumption in 1993 over that of 1992 was mainly due to the increase in area cultivated under paddy during that year which indicates the positive relationship between fertilizer consumption with extent under paddy. Continuing the increasing trend in 1994, the fertilizer usage in paddy sector reached a record level representing around 14 per cent growth over the previous year. Increase in area under paddy around 11 per cent over the previous year and re introduction of fertilizer subsidy in October 1994 were the major factors that contributed to this increase.

Consequent to the removal of fertilizer subsidy, there was about two-fold increase in the prices of all subsidized fertilizers. However, due to the action taken by the government to increase farm gate price of paddy helped farmers to minimize the adverse impact of sudden increase in fertilizer prices. The drastic increase in selling prices of fertilizers were seen in 1991 as several local price revisions were done according to the world market price changes.

Figure 5 : Changes in Fertilizer Prices and Farm gate Price of paddy in Period II

\begin{tabular}{|l|l|l|l|l|}
\hline Changes in Fertilizer Prices & \multicolumn{3}{c|}{$\begin{array}{c}\text { Changes in Farm gate Price of } \\
\text { Paddy }\end{array}$} \\
\hline \\
\hline
\end{tabular}


However, during the period 1991 to October 1994, fertilizer prices remained stable. Drastic change in fertilizer prices occurred with the reintroduction of fertilizer subsidy in 10 October 1994 by the new government that came in to power. Accordingly, four main fertilizers were subsidized by about 30 per cent of their retail price.

The increasing trend in farm gate price of paddy that started in 1990 continued until 1993. With the increase in marketable paddy surplus in 1994, the farm gate price of paddy dropped by 13 per cent. However, the drop in paddy prices did not affect fertilizer consumption in 1994 since fertilizer prices were reduced by the reintroduction of fertilizer subsidy during the fourth quarter of the year.

\section{Period III (1997-2004) - Subsidy Provided only for Urea}

There was a drastic change in the fertilizer subsidy scheme in October 1997 as it restricted fertilizer subsidy only to urea. The objective of this change was to provide a higher benefit to paddy farmers who were the main users of urea. Past statistics indicate approximately 75 per cent of Urea used in the country was utilized for the paddy sector, which is dominated by small-scale farmers. Therefore, the government decided to confine the subsidy scheme for urea only with a view to pass on the benefits of the scheme to small-scale farmers. The subsidy rates were announced in rupee terms and it was decided to review the subsidy amount on a seasonal basis maintaining the retail price of Urea unchanged during the period. In 2002, the subsidy scheme was revised with increased international prices. Accordingly a fixed sum of subsidy was

Figure 6 : Changes in Fertilizer Usage in Period III

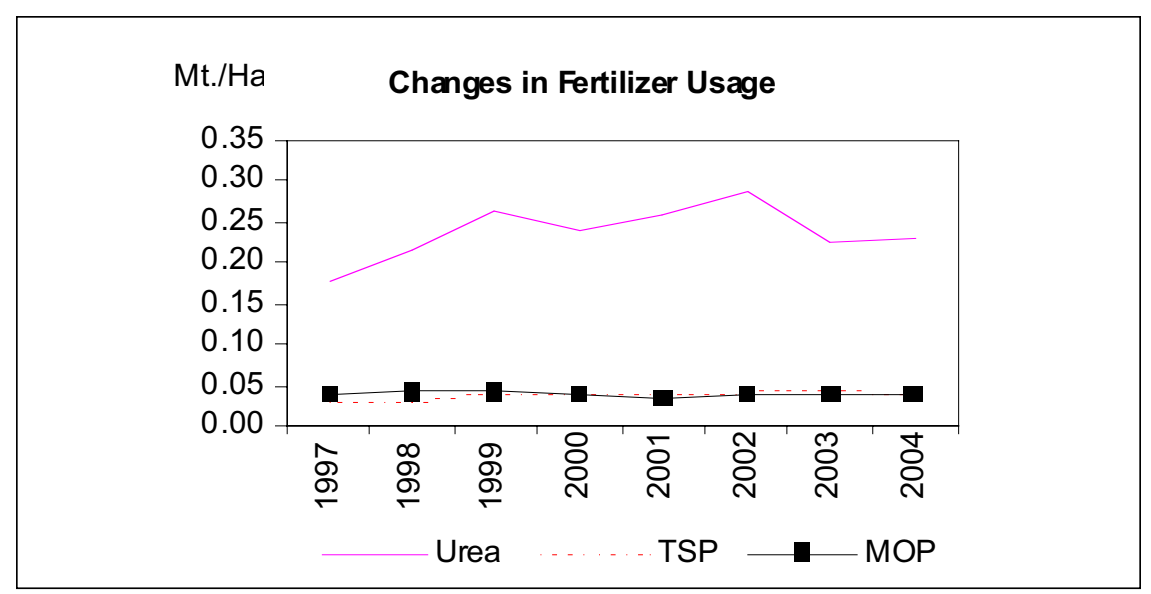


given to urea importers allowing retail prices to be varied according to the world market prices of fertilizer. However, in 2004 the new government came in to power and it was decided to fix retail price of Urea again to avoid severe fluctuations in retail price.

With the commencement of new subsidy scheme in 1997, use of fertilizer for paddy decreased marginally over the previous year. This was entirely due to the reduction in the use of TSP and MOP, since Urea usage increased by 1.6 per cent during the period. Use of fertilizer for paddy recovered in 1998 due to the increase in usage of highly subsidized Urea by 20.6 per cent over that of 1997. However, use of MOP increased marginally while application of TSP decreased over the previous year. In 1999, use of Urea for paddy increased substantially to a record level, indicating that paddy farmers benefited most from the fertilizer subsidy scheme. Use of TSP for paddy too increased in 1999 , even though it was not proportionate to maintained the N:P:K ratio in the overall fertilizer use.

In line with the decline in area cultivated in 2000, the total fertilizer use for paddy dropped by 18 per cent. However, it was recovered in 2001 and fertilizer usage for paddy increased by 10.6 per cent despite the drought experienced during the year. This trend continued in 2002 as well. In 2003, use of fertilizer dropped significantly mainly due to the rise in fertilizer prices as a result of the revision of fertilizer subsidy scheme in October 2002 with the increased price in the international market. Under the revised scheme a fixed sum of Rs.6,000 per metric ton was given as a subsidy payment for Urea importers. This scheme was continued until May 2004. The new government reintroduced subsidy scheme with fixed retail price and as a result Urea usage increased slightly over the previous year.

With the introduction of new subsidy scheme in 1997, there were major price revisions during the years. The sale price of Urea was maintained at the

Figure 7 : Changes in Fertilizer Prices and Farm gate Price of paddy in Period III

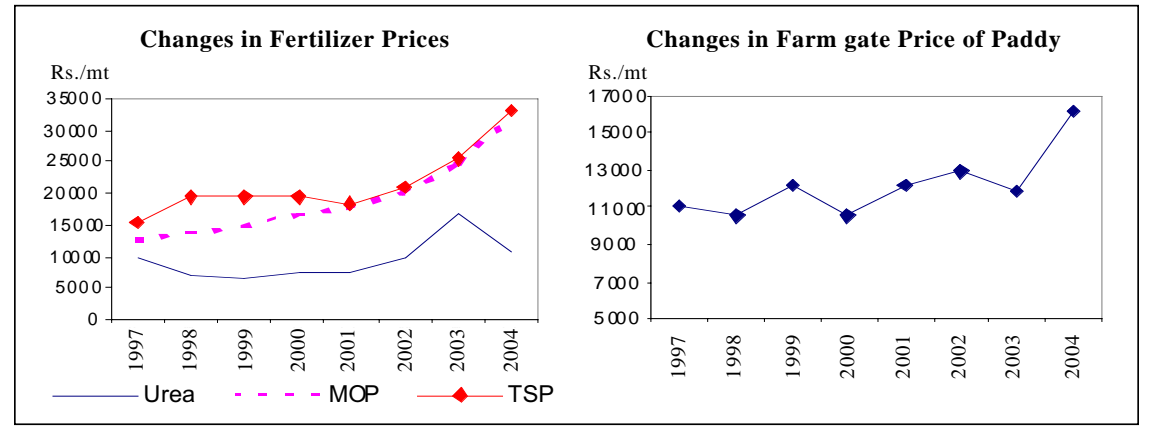


indicative price under the fertilizer subsidy scheme. Prices of other fertilizers were determined by the market considering the factors such as appreciation of US\$, price fluctuations in the international market and freight rates. With the increase demand for Urea owing to the subsidized price there was a stiff competition among sellers and hence the actual price of Urea operated below the indicative price of the government. As a result Urea price came down and remain static until 2002 while prices of other fertilizers moved upward with increase in import prices. In 2002 with the change in fertilizer subsidy scheme annual average price of Urea increased to Rs.9,400 per metric ton in 2002 from Rs.7,000 per metric ton prevailed in 2001. The urea price was further increased in 2003 and reached highest ever retail price of Rs.17,000 per metric ton as at end 2003. However, with the reintroduction of fixed retail price in 2004 , the price of urea dropped significantly over that of previous year.

Paddy price, which is mainly determined by the supply conditions, heavily fluctuated during the period. In 1998, with the increased paddy production, the average producer price of paddy declined over the previous year. However, this price remained well above the guaranteed price of paddy. In contrast to the normal behaviour, in 2000 the farm gate price of paddy declined mainly due to rice importation even though the paddy production also dropped. In 2001 the farm gate price increased and maintained at a higher level until 2003. Paddy price dropped in 2003 with the record level harvest and increased again in 2004 with the drop in paddy production due to severe drought prevailed in the country. Fertilizer usage in 2003 was highly affected by the dropped in paddy price and also due to increased fertilizer price under the revised subsidy scheme.

According to the above analyse it reveals that fertilizer usage can be influenced by fertilizer price, producer price of paddy and extent under paddy cultivation. Hence to estimate the sensitivity of these variables to fertilizer usage separate demand functions were employed by using 25 years of data.

\section{B. Estimation of Fertilizer Demand Functions}

\section{Demand Function: Urea}

Prior to engage in performing econometric analysis, all variables in log form were subjected to Augmented Dicky Fuller (ADF) unit root tests to verify their time series properties. The results were also tested by using Philips Perron (PP) test. 
Table 1 : Unit Root Test - Variables in Levels

\begin{tabular}{|l|c|c|}
\hline Variable in levels & ADF & PP \\
\hline UQ (Urea Usage) & -1.114992 & -0.820758 \\
UP (Urea Price) & -1.882988 & -1.824195 \\
PP (Paddy Price) & -1.116489 & 1.681542 \\
EX (Extent) & -1.227110 & -0.986910 \\
\hline
\end{tabular}

* Significant at $5 \%$ level

Since all the variables were found to be non-stationary on levels, unit root test were carried out on first differences. As indicated below all first difference series were stationary at a very high levels of significance. Therefore, it was concluded that all the series were I(I).

Table 2 : Unit Root Test - Variables in First Difference

\begin{tabular}{|l|c|c|}
\hline Variables in 1st Difference & ADF & PP \\
\hline UQ1 & $-4.890511 * *$ & $-5.319587 * *$ \\
UP1 & $-5.159817 * *$ & $-5.214621 * *$ \\
PP1 & $-5.324109 * *$ & $-5.359762 * *$ \\
EX1 & $-5.403066 * *$ & $7.241751 * *$ \\
\hline
\end{tabular}

** Significant at $1 \%$ level

Given that urea usage, urea price, paddy price and extent under irrigation were $\mathrm{I}(\mathrm{I})$, simple linear regression analysis was carried out to estimate size and significance of those variables to urea usage. The model used is as follows.

$$
\begin{aligned}
\mathbf{Q}_{t} & =\mathbf{f}\left\{\left(\mathbf{P}_{(f)(t)}\right),\left(\mathbf{P}_{(p)(t-1)}\right),\left(\mathbf{E}_{(\boldsymbol{p})(t)}\right),\left(\mathbf{D}_{\mathbf{1}}\right)\right\} \\
\mathrm{Q}_{t} & - \text { Quantity of fertilizer }(\mathrm{mt}) \text { used in year } t \\
\mathrm{P}_{(f)(t)} & - \text { Price of Fertilizer (Rs./mt) in year } t \\
\mathrm{P}_{(p)(t-1)} & - \text { Farm Gate price paddy (Rs./mt) in year } t-1 \\
\mathrm{E}_{(p)(t)} & - \text { Paddy Extent under Irrigation in year } t \\
\mathrm{D}_{1} & - \text { Dummy for policy changes }
\end{aligned}
$$


Table 3 : Results of the regression - Urea

\begin{tabular}{llllr}
$\begin{array}{l}\text { Dependent Variable } \\
\text { Method }\end{array}$ & $\begin{array}{l}\text { : UQ1 } \\
\text { Sample (adjusted) }\end{array}$ & $\begin{array}{l}\text { Least Squares } \\
: 1981-2004\end{array}$ & & \\
Included observations & $: 24$ after adjusting endpoints & & \\
\hline \multicolumn{1}{c}{ Variable } & Coefficient & Std. Error & t-Statistic & Prob. \\
\hline C & -0.611588 & 2.888294 & -0.211747 & 0.8346 \\
UP1 & -0.154291 & 0.087234 & -1.768702 & 0.0930 \\
PP1(-1) & 0.330789 & 0.150557 & 2.197098 & 0.0406 \\
EX1 & 2.532465 & 0.895402 & 2.828298 & 0.0107 \\
DU & 0.182554 & 0.071723 & 2.545274 & 0.0198 \\
\hline R-squared & 0.913806 & Mean dependent var & 11.87652 \\
Adjusted R-squared & 0.895660 & S.D. dependent var & 0.287835 \\
S.E. of regression & 0.092976 & Akaike info criterion & -1.729909 \\
Sum squared resid & 0.164245 & Schwarz criterion & -1.484481 \\
Log likelihood & 25.75891 & F-statistic & 50.35847 \\
Durbin-Watson stat & 1.972436 & Prob (F-statistic) & 0.000000 \\
\hline
\end{tabular}

Results show that all the selected variables are significant for urea usage with theoretically expected signs. Further, these results indicate that fertilizer demand is inelastic to own price, cross price and policy changes. However, extent under irrigation is highly sensitive to urea usage, which implies that increasing the total area under paddy under irrigation would have a higher impact on the urea application. Previous researches also observed that the input use is higher under irrigated conditions than in rain fed lands in the country.

Inelasticity of urea usage to its own price, cross price and policy changes suggests that unavailability of substitutes for urea encourage farmers to apply urea with out considering price changes. According to the results a one-unit increase in price of a metric ton of urea would reduce annual urea demand for paddy by 0.15 units. If lagged farm gate price increases by one unit per metric ton, urea demand will increase by 0.33 units. This information reveals that fertilizer demand is more sensitive to change in paddy price than to change in fertilizer prices. If fertilizer prices were increased holding paddy prices constant a reduction in urea use would occur.

\section{Demand Function: Muriate of Potash (MOP)}

At first all the variables in log form that use to analyse MOP demand function were tested for stationary. The ADF tests showed that all variables are 
stationary in first difference, i.e., I(I) and the results were confirmed by Philips Perron tests.

Table 4 : Unit Root Test - Variables in First Difference

\begin{tabular}{|l|c|c|}
\hline Variables in 1st Difference & ADF & PP \\
\hline MOPQ1 (MOP usage) & $-4.164773 * *$ & $-5.048492 * *$ \\
MOPP1 (MOP price) & $-6.095492 * *$ & $-6.095492 * *$ \\
PP1 (Paddy Price) & $-5.324109 * *$ & $-5.359762 * *$ \\
EX1 (Extent) & $-5.403066 * *$ & $-7.241751 * *$ \\
\hline
\end{tabular}

** Significant at $1 \%$ level

A Simple linear regression was carried out to estimate size and significance of those variables to MOP usage. Since there is a tendency to use of urea excessively than other fertilizers due to its lower price, in analyzing MOP demand function, the Urea price is also taken as an independent variable. The model used is as follows.

$$
\begin{gathered}
\mathbf{Q}_{t}=\mathbf{f}\left\{\left(\mathbf{P}_{(f)(t)}\right),\left(\mathbf{P}_{(p)(t-1)}\right),\left(\mathbf{E}_{(p)(t)}\right),\left(\mathbf{D}_{2}\right)\right\} \\
\mathrm{Q}_{t}-\text { Quantity of fertilizer }(\mathrm{mt}) \text { used in year } t \\
\mathrm{P}_{(f)(t)}-\text { Price of Fertilizer }(\mathrm{Rs} . / \mathrm{mt}) \text { in year } t \\
\mathrm{P}_{(p)(t-1)}-\text { Farm Gate price paddy }(\mathrm{Rs} . / \mathrm{mt}) \text { in year } t-1 \\
\mathrm{E}_{(p)(t)}-\text { Paddy Extent under Irrigation in year } t \\
\mathrm{D}_{2}-\text { Dummy for policy changes }
\end{gathered}
$$

Results show that except extent under irrigation all other selected variables are significant for MOP Usage with theoretically expected signs. Similar to the results of the Urea demand function, results of the MOP demand function indicates that MOP demand is inelastic to own price, cross price and policy changes.

Inelasticity of MOP usage to its own price, cross price and policy changes implies that since there are no substitute available for MOP, farmers tend to apply MOP without considering price changes. According to the results, a one-unit increase in price of a metric ton of MOP would reduce its annual demand for paddy by 0.21 units. If lagged farm gate price increases by one unit per metric ton, MOP demand will increase by 0.79 units. These results 
Table 5 : Results of the regression - MOP

\begin{tabular}{lclrr}
$\begin{array}{l}\text { Dependent Variable } \\
\text { Method }\end{array}$ & $\begin{array}{l}\text { : MOPQ1 } \\
\text { Sample (adjusted) } \\
\text { Seast Squares } \\
\text { Included observations }\end{array}$ & \multicolumn{1}{c}{ l981-2004 } \\
: 24 after adjusting endpoints & & \\
\hline \multicolumn{1}{c}{ Variable } & Coefficient & Std. Error & t-Statistic & Prob. \\
\hline C & 4.494407 & 2.981188 & 1.507589 & 0.1481 \\
MOPP1 & -0.212730 & 0.117575 & -1.809312 & 0.0863 \\
PP1(-1) & 0.792315 & 0.235511 & 3.364243 & 0.0033 \\
EX1 & 0.149572 & 0.978238 & 0.152900 & 0.8801 \\
D2 & 0.248983 & 0.091279 & 2.727709 & 0.0134 \\
\hline R-squared & 0.739215 & Mean dependent var & 10.33500 \\
Adjusted R-squared & 0.684313 & S.D. dependent var & 0.211380 \\
S.E. of regression & 0.118766 & Akaike info criterion & -1.240272 \\
Sum squared resid & 0.268002 & Schwarz criterion & -0.994844 \\
Log likelihood & 19.88326 & F-statistic & 13.46425 \\
Durbin-Watson stat & 1.337459 & Prob (F-statistic) & 0.000023 \\
\hline
\end{tabular}

also confirm that the fertilizer demand is more sensitive to change in paddy price than to change in fertilizer prices. Further, in the case of MOP demand, own price and cross price elasticities are relatively higher than in Urea demand.

\section{Demand Function: Triple Super Phosphate (TSP)}

Except quantity used and the fertilizer price, all the other variables were similar to the previous estimation. Since the ADF tests confirmed that all variables are stationary in first difference, i.e., I(I), a simple linear regression were carried out to estimate TSP demand function. The Urea price was taken as an independent variable for this analysis too. The Model and variables are given bellow.

$$
\begin{gathered}
\mathbf{Q}_{t}=\mathbf{f}\left\{\left(\mathbf{P}_{(f)(t)}\right),\left(\mathbf{P}_{(\boldsymbol{p})(t-\mathbf{1})}\right),\left(\mathbf{E}_{(\boldsymbol{p})(t)}\right),\left(\mathbf{D}_{2}\right)\right\} \\
\mathrm{Q}_{t}-\text { Quantity of fertilizer }(\mathrm{mt}) \text { used in year } t \\
\mathrm{P}_{(f)(t)}-\text { Price of Fertilizer (Rs./mt) in year } t \\
\mathrm{P}_{(p)(t-1)}-\text { Farm Gate price paddy (Rs./mt) in year } t-1 \\
\mathrm{E}_{(p)(t)}-\text { Paddy Extent under Irrigation in year } t \\
\mathrm{D}_{2}-\text { Dummy for policy changes }
\end{gathered}
$$


Table 6 : Results of the regression - TSP

\begin{tabular}{lclrr}
$\begin{array}{l}\text { Dependent Variable } \\
\text { Method }\end{array}$ & $\begin{array}{l}\text { : TSPQ1 } \\
\text { Sample (adjusted) } \\
\text { Seast Squares } \\
\text { Included observations }\end{array}$ & \multicolumn{1}{c}{ l981-2004 } \\
& 24 after adjusting endpoints & & \\
\hline \multicolumn{1}{c}{ Variable } & Coefficient & Std. Error & t-Statistic & Prob. \\
\hline C & 1.336310 & 3.500426 & 0.381756 & 0.7069 \\
TSPP1 & -0.075420 & 0.151730 & -0.497065 & 0.6248 \\
EX1 & 1.365139 & 1.138181 & 1.199405 & 0.2451 \\
PP1(-1) & 0.414735 & 0.290252 & 1.428878 & 0.1693 \\
D2 & 0.273064 & 0.110374 & 2.473980 & 0.0230 \\
\hline R-squared & 0.632031 & Mean dependent var & 10.24918 \\
Adjusted R-squared & 0.554564 & S.D. dependent var & 0.207979 \\
S.E. of regression & 0.138807 & Akaike info criterion & -0.928408 \\
Sum squared resid & 0.366082 & Schwarz criterion & -0.682980 \\
Log likelihood & 16.14090 & F-statistic & 8.158690 \\
Durbin-Watson stat & 2.058493 & Prob (F-statistic) & 0.000026 \\
\hline
\end{tabular}

Even though results confirmed theoretically expected signs, most of the variables are not significant for TSP demand. According to the results, changes in fertilizer price, out put price and the cheapest fertilizer price could not influence the TSP demand significantly.

\section{Conclusion}

Findings in section IV indicate that even though there are some similarities, fertilizer demand functions could vary according to the type of fertilizer. Selected main fertilizers are inelastic to its' own price, output price and policy changes with different significance levels. Therefore, it could be concluded that the fertilizer demand is not significantly affected by changes in own price, output price and related policies in the short run and hence fertilizer subsidy is not a key determinant of fertilizer usage in paddy cultivation. These results were also in line with the findings of related research in other countries. Since the unavailability of substitutes for fertilizer, farmers tend to apply fertilizer with whatever difficulties to ensure the optimum yield levels. However, increase in fertilizer price could reduce farmers' profit since it increases cost of production.

Further, these results also revealed that own price elasticity of demand for fertilizer was smaller than cross price elasticity between demand for 
fertilizer and paddy price. Therefore, increasing paddy price would increase demand for fertilizer at a faster rate than when decreasing fertilizer prices. Increasing paddy prices or decreasing fertilizer prices are the alternatives available to the government to provide incentives to the paddy farmers in the short run. Even though increase in output price could play a greater role in this regard, such a policy would spread the farmers' problem over the entire society.

Hence, policy makers should weigh pros and cons of two options available before making a decision. However, a sudden withdrawal of the subsidy will push farmers in low-income groups into worse situation than they were in the past. At least there should be a way to group farmers according to their income levels and to help low income group with subsidies. Therefore, well-targeted subsidy scheme, which is subjected to gradual phase out, is preferred in the short run. The government's decision of restricting fertilizer subsidy only for paddy farmers from 2006 is an important step taken for this direction.

It is also revealed that farmers had not been using correct amount of fertilizer to maintain $\mathrm{N}: \mathrm{P}: \mathrm{K}$ ratio of the field especially during the period III (1997 - 2004) in which only urea was subsidized. This situation should also be corrected through a sound agricultural extension programme. Further, it will reduce cost of production by increasing average yield.

Meanwhile, public expenditure should also be focused on providing infrastructure as well as institutional facilities that are required to improve efficiency in paddy marketing to allow paddy price to be attractive. Once productivity and profitability in paddy cultivation is increased to an acceptable level fertilizer subsidy could be withdrawn completely. 


\section{References}

Boyle, G.E., (1982), “Modelling Fertilizer Demand in the Republic of Ireland: A Cost Function Approach", Journal of Agricultural Economics, Vol. 33.

Burrell, A., (1982), "The Demand for Fertilizer in the United Kingdom", Journal of Agricultural Economics, Vol. 40:1-20.

Central Bank of Sri Lanka, Annual Reports, various issues.

Chandrapala, H.A. and De Silva, S., (1988), "Economics of Fertilizer use in major Crop sectors of Sri Lanka", Staff Studies, Central Bank of Sri Lanka (CBSL).

Griliches, Z., (1958), “The Demand for Fertilizer: An Economic Interpretation of a Technical Change", Journal of Farm Economics, Vol. 40 (3).

Griliches, Z., (1959), “Distributed Lags, desegregation and Regional Demand Function for Fertilizer", Journal of Farm Economics, Vol. 41 (2).

Gunawardena, P. and Flinn C. J., (1987), "Supply Response and Fertilizer demand in Rice sector in Sri Lanka", Quarterly Journal of International Agriculture, Vol. 26 (4).

Heady, E.O. and Yeh, M. H., (1959), "National and Regional Demand Function for Fertilizer", Journal of Farm Economics, Vol. 41 (2).

National Fertilizer Secretariat,“Fertilizer Review” various issues.

Rice Research Institute, (2004), "Fertilizer Recommendations for Paddy", Internal Circular. 


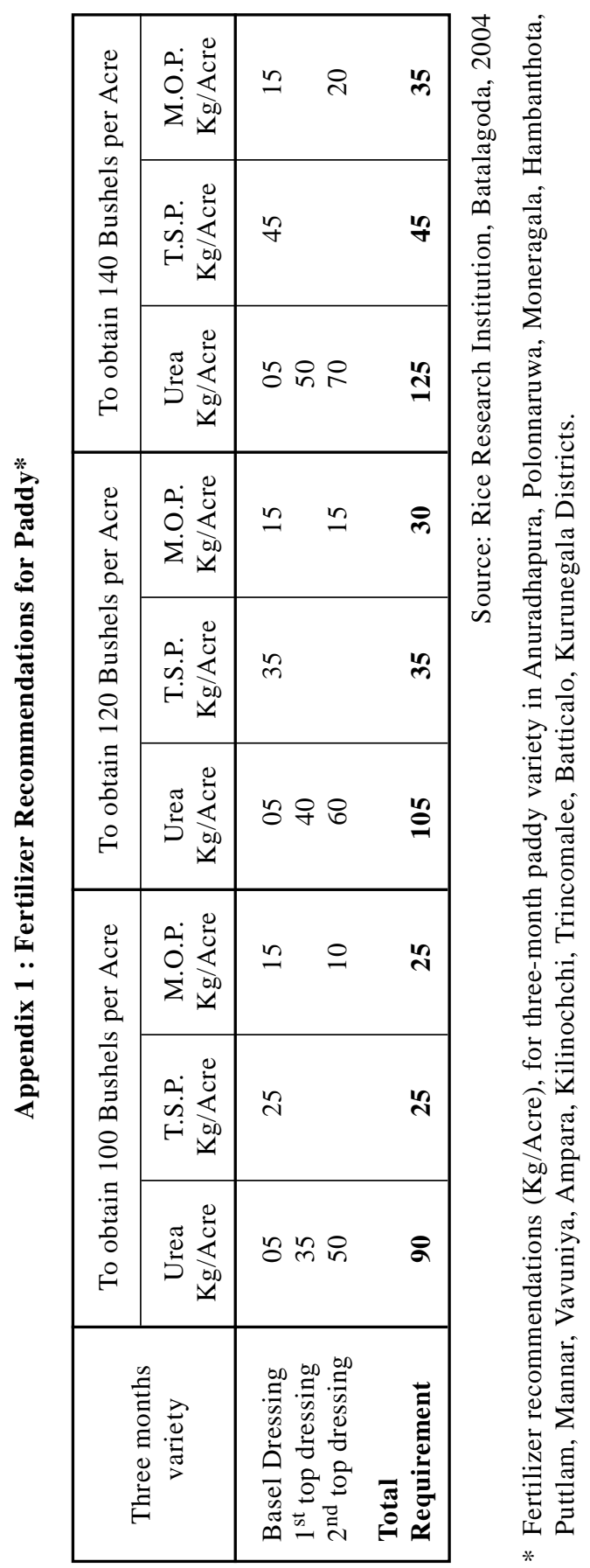


Appendix 2 : Public Expenditure on Fertilizer Subsidy

\begin{tabular}{|l|c|c|}
\hline \multicolumn{1}{|c|}{ Year } & $\begin{array}{c}\text { Expenditure } \\
\text { (Rs.mn) }\end{array}$ & $\begin{array}{c}\text { As a Percentage } \\
\text { of GDP }\end{array}$ \\
\hline 1987 & 600 & 0.27 \\
1988 & 347 & 0.32 \\
$1989-1993$ & - & - \\
1994 & 630 & 0.1 \\
1995 & 1,345 & 0.2 \\
1996 & 1,500 & 0.2 \\
1997 & 1,895 & 0.2 \\
1998 & 2,152 & 0.2 \\
1999 & 1,390 & 0.1 \\
2000 & 1,733 & 0.1 \\
2001 & 3,650 & 0.3 \\
2002 & 2,448 & 0.2 \\
2003 & 2,191 & 0.1 \\
2004 & 3,572 & 0.2 \\
\hline
\end{tabular}

Source: Central Bank Annual Reports

Appendix 3 : Annual Average Retail Price of Fertilizer

\begin{tabular}{|c|c|c|c||r|r|r|c|}
\hline Year & Urea & MOP & \multicolumn{1}{c|}{ TSP } & Year & Urea & MOP & TSP \\
\hline 1981 & 2,463 & 2,565 & 2,375 & 1993 & 9,850 & 9,500 & 10,300 \\
1982 & 2,785 & 2,900 & 2,685 & 1994 & 9,850 & 9,500 & 10,300 \\
1983 & 2,850 & 2,750 & 2,850 & 1995 & 10,200 & 10,196 & 11,204 \\
1984 & 2,850 & 2,750 & 2,850 & 1996 & 11,000 & 11,250 & 12,200 \\
1985 & 2,850 & 2,750 & 2,850 & 1997 & 9,400 & 12,625 & 15,375 \\
1986 & 2,850 & 2,750 & 2,850 & 1998 & 6,800 & 13,500 & 19,200 \\
1987 & 2,850 & 2,750 & 2,850 & 1999 & 6,300 & 14,633 & 19,200 \\
1988 & 3,650 & 3,550 & 3,650 & 2000 & 7,000 & 16,500 & 19,200 \\
1989 & 3,650 & 3,550 & 3,650 & 2001 & 7,000 & 17,550 & 18,200 \\
1990 & 7,900 & 8,200 & 9,650 & 2002 & 9,450 & 19,940 & 21,000 \\
1991 & 10,000 & 9,367 & 10,050 & 2003 & 17,000 & 24,500 & 25,500 \\
1992 & 9,850 & 9,500 & 10,300 & 2004 & 10,740 & 32,200 & 33,250 \\
\hline
\end{tabular}

Source: National Fertilizer Secretariat 
Appendix 4 : Annual Use of Fertilizer in Paddy Cultivation

000'Mt

\begin{tabular}{|r|r|r|c||c|c|c|c|}
\hline Year & \multicolumn{1}{|c|}{ Urea } & TSP & MOP & Year & Urea & TSP & MOP \\
\hline 1980 & 116.2 & 18.3 & 17.1 & 1993 & 136.5 & 37.7 & 32.7 \\
1981 & 94.6 & 17.7 & 16.4 & 1994 & 161.5 & 35.2 & 40.1 \\
1982 & 97.3 & 22.2 & 21.8 & 1995 & 157.6 & 34.6 & 40.0 \\
1983 & 97.0 & 21.8 & 23.0 & 1996 & 147.0 & 34.8 & 36.9 \\
1984 & 112.6 & 25.1 & 24.5 & 1997 & 149.3 & 26.8 & 32.7 \\
1985 & 125.0 & 28.0 & 27.8 & 1998 & 180.1 & 23.7 & 34.6 \\
1986 & 139.7 & 36.3 & 32.4 & 1999 & 234.2 & 34.1 & 38.4 \\
1987 & 133.0 & 28.8 & 31.9 & 2000 & 193.3 & 27.1 & 29.8 \\
1988 & 131.0 & 28.6 & 33.8 & 2001 & 214.4 & 32.9 & 29.5 \\
1989 & 139.1 & 32.0 & 32.0 & 2002 & 270.1 & 37.2 & 37.5 \\
1990 & 99.2 & 20.5 & 26.0 & 2003 & 201.9 & 38.2 & 33.2 \\
1991 & 98.2 & 22.8 & 29.8 & 2004 & 222.2 & 34.8 & 36.6 \\
1992 & 118.9 & 24.2 & 32.3 & & & & \\
\hline
\end{tabular}

Source: National Fertilizer Secretariat 